\title{
Efeito alelopático de folhas de bamburral [Hyptis suaveolens (L.) Poit.] sobre a germinação de sementes de sorgo (Sorghum vulgare Pers.), rabanete (Raphanus sativus L.) e alface (Lactuca sativa L.)
}

\author{
RODRIGUES, A.C. ${ }^{1}$; ARTIOLI, F.A. ${ }^{1}$; POLO, M. ${ }^{2 *}$; BARBOSA, L.C.A. ${ }^{3}$; BEIJO, L.A. ${ }^{4}$ \\ ${ }^{1}$ Laboratório de Plantas Medicinais, Universidade Federal de Alfenas, Rua Gabriel Monteiro da Silva, 700, CEP: \\ 37130-000, Alfenas-Brasil ' Laboratório de Biotecnologia e Genética Vegetal, Instituto de Ciências da Natureza \\ ${ }^{4}$ Instituto de Ciências Exatas, Universidade Federal de Alfenas, Rua Gabriel Monteiro da Silva, 700, CEP: 37130- \\ 000, Alfenas-Brasil *marcelo.polo@unifal-mg.edu.br ${ }^{3}$ Departamento de Química, Universidade Federal de Viçosa, \\ CEP: 36571-000, Viçosa-Brasil
}

\begin{abstract}
RESUMO: O objetivo do presente trabalho foi à verificação do efeito alelopático de Hyptis. suaveolens na germinação de sorgo, alface e rabanete, bem como, a comprovação da existência de compostos com potencial alelopático. Sementes de sorgo, alface e rabanete foram semeadas em substrato constituído de areia, terra e adubo orgânico contendo folhas de $H$. suaveolens. As análises da germinação foram feitas considerando a protrusão da radícula para o término do evento germinativo. Foi calculado o IVG (índice de velocidade de germinação) e \%G (porcentagem de germinação). Os resultados mostraram que sorgo e a alface foram mais susceptíveis ao potencial alelopático de $\mathrm{H}$. suaveolens, sendo que para o rabanete foi observado um efeito benéfico. Entre os tratamentos, o substrato esterilizado e não esterilizado mostraram diferenças entre si. A análise cromatográfica do óleo essencial presente nas folhas de $H$. suaveolens revelou a presença de compostos com potencial alelopático. Portanto, $H$. suaveolens, pode apresentar efeito alelopático positivo no IVG de sementes de rabanete e a presença de microorganismos pode ser necessária para que esse efeito alelopático aconteça.
\end{abstract}

Palavras-chave: folhas de Hyptis suaveolens, efeito alelopático, germinação de sementes

ABSTRACT: Allelopathic effects of leaves of "bamburral" [Hyptis suaveolens (L.) Poit.] on the germination of seeds of sorghum (Sorghum vulgare Pers.), radish (Raphanus sativus L.) and lettuce (Lactuca sativa L.). The aim of this study was to verify the allelopathic effect of $H$. suaveolens on the germination of sorghum, lettuce and radish, as well as to prove the existence of compounds with allelopathic potential. Seeds of sorghum, lettuce and radish were sown in substrate consisting of sand, soil and organic fertilizer containing leaves of $H$. suaveolens. The germination tests were performed considering the protrusion of the radicle for the conclusion of the germinative event. GSI (germination speed index) and G\% (percentage of germination) were calculated. The results showed that sorghum and lettuce were more susceptible to the allelopathic potential of $H$. suaveolens, while for radishes a beneficial effect was observed. Between treatments, the sterilized and unsterilized substrate showed differences. The chromatographic analysis of essential oil present in the leaves of $H$. suaveolens revealed the presence of compounds with allelopathic potential. Therefore, $H$. suaveolens may have positive allelopathic effect on the GSI of radish seeds, and the presence of microorganisms may be necessary for such an allelopathic effect to occur.

Key words: leaves of Hyptis suaveolens, allelopathic effect, seed germination

\section{INTRODUÇÃO}

A alelopatia pode ser definida de várias maneiras, sendo considerado um processo pelo qual produtos do metabolismo secundário de determinado vegetal são liberados, impedindo a germinação e o desenvolvimento de outras plantas relativamente próximas (Soares \& Vieira, 2000). Ou ainda, a alelopatia é um mecanismo de interação, definido por Rice (1984) como qualquer efeito direto ou indireto,

Recebido para publicação em 19/07/2010

Aceito para publicação em 15/03/2012

Rev. Bras. Pl. Med., Botucatu, v.14, n.3, p.487-493, 2012. 
danoso ou benéfico, que uma planta, inclusive microorganismos, exerce sobre outra pela produção de substâncias químicas liberadas no ambiente.

Os efeitos alelopáticos são mediados através de substâncias químicas pertencentes a diferentes categorias de compostos, tais como fenóis, terpenos, alcalóides, poliacetilenos, ácidos graxos, peptídeos, entre outros. Essas substâncias químicas estão presentes em diferentes órgãos, incluindo folhas, flores, frutos e gemas de muitas espécies vegetais (Miró et al., 1997; Delachiave et al., 1999).

Efeitos alelopáticos já foram comprovados em várias espécies que possuem estas substâncias, como em canela, alecrim-pimenta, capim-citronela e alfavaca-cravo, que afetam a germinação de alface (Alves et al., 2004). Para verificar os efeitos de alelopatia, sementes de sorgo, alface e rabanete podem ser utilizadas, principalmente por apresentarem germinação rápida e uniforme e serem consideradas sensíveis, pois expressam de forma satisfatória os efeitos que compostos secundários podem ter sobre a germinação (Alves et al., 2004).

Hyptis suaveolens (L.) Poit é uma espécie da família Lamiaceae, produtora de óleo essencial rico em terpenóides (Martins et al., 2006), que compreende mais de 400 espécies, ocorrendo em todo o mundo (Peerzada, 1997). É um gênero rico em espécies de grande importância econômica e etnofarmacológica (Falcão \& Menezes, 2003). $H$. suaveolens é conhecida vulgarmente no Brasil como bamburral (nordeste) e erva-canudo (sudeste e sul), onde é considerada invasora de lavouras de milho (Polo \& Felippe, 1983) e de pastagens (Silva et al., 2003). A face abaxial das folhas é densamente coberta por tricomas glandulares (Silva et al., 2003), que aparecem em menor densidade na face adaxial (Martins \& Polo, 2009). Diferenças quantitativas e qualitativas na composição do óleo essencial de $H$. suaveolens são percebidas claramente, evidenciando mecanismos de regulação dependentes de variações nas condições ambientais e endógenas (Martins et al., 2006).

O objetivo deste trabalho foi a verificação do efeito alelopático das folhas de $H$. suaveolens na germinação de alface (Lactuca sativa), sorgo (Sorghum vulgare) e rabanete (Raphanus sativus) em substrato esterilizado e não esterilizado, e verificar a existência de terpenos nas folhas desta espécie, caracterizando compostos com possível potencial alelopático.

\section{MATERIAL E MÉTODO}

Folhas de $H$. suaveolens foram coletadas de indivíduos em fase de floração, no cerrado de Boa Esperança (MG), microrregião do baixo Sapucaí, às margens do Lago de Furnas, nas coordenadas $21^{\circ} 05^{\prime} 15^{\prime \prime}$ LS e $45^{\circ} 35^{\prime} 02^{\prime \prime}$ LW. Devido à baixa produção de flores e o tamanho relativamente pequeno das mesmas, com cerca de $5 \mathrm{~mm}$ de comprimento (Polo, 1982), foram utilizadas as folhas como possível agente alelopático. A escolha de indivíduos no estágio de florescimento foi devido a não disponibilidade no campo de indivíduos no estágio vegetativo. Uma exsicata da espécie encontra-se incorporada ao herbário do Instituto de Ciências da Natureza da UNIFAL-MG com o número UFAL 047. A coleta foi feita manualmente nos meses de março e abril de 2008. Para testar o efeito alelopático das folhas de $H$. suaveolens sementes de sorgo, rabanete e alface foram adquiridas em casas comerciais de produtos agrícolas e correspondem às variedades Matrix 610, Vip Crimson S. Especial e Monica SF 31 , para sorgo, rabanete e alface, respectivamente. Os tratamentos foram divididos em substrato esterilizado com folhas (EF), substrato esterilizado sem folhas (ESF), substrato não esterilizado com folhas (NEF) e substrato não esterilizado sem folhas (NESF).

Os testes foram conduzidos em caixas de germinação (Gerbox ${ }^{\circledR}$ ). Como substrato foi utilizado uma mistura de terra, areia e matéria orgânica na proporção de 3:2:1 (v:v:v). Parte do substrato foi esterilizado em estufa a $105^{\circ} \mathrm{C}$ por 24 horas. $\mathrm{O}$ volume de substrato utilizado em cada caixa foi de $200 \mathrm{~mL}$ e 2,45 gramas de folhas picotadas por caixa, equivalente a área foliar média de $623,7 \mathrm{~cm}^{2}$. A metodologia de incorporação de folhas no substrato e a quantidade utilizada seguiram a metodologia proposta por Souza et al. (2006) com reduções na quantidade de material incorporado devido a disponibilidade de espaço nas caixas gerbox. As sementes foram semeadas após 24 horas de incorporação das folhas no substrato. A escolha desse tempo de exposição foi devido a observações de folhas coletadas que perdem o aroma rapidamente, o que pode estar relacionado à volatilização do óleo essencial.

Foram distribuídas 25 (vinte e cinco) sementes por caixa, com quatro repetições por tratamento. As sementes ficaram dispostas a dois $\mathrm{cm}$ da borda do Gerbox. As caixas foram mantidas em câmara de germinação Eletrolab modelo 122 FC, em 10 prateleiras distribuídas uniformemente e sob quatro lâmpadas fluorescentes laterais tipo "luz do dia" de $20 \mathrm{~W}$ cada. A temperatura foi mantida a $25^{\circ} \mathrm{C}$ constante. As sementes foram consideradas germinadas a partir da protrusão da radícula e a contagem da germinação foi feita de 12 em 12 horas, durante 120 horas, sendo este período suficiente para definir a germinação.

Após a avaliação da germinação foi calculado a porcentagem de germinação $(\% G)$ e o índice de velocidade de germinação (IVG). A \% foi 
calculada pela seguinte fórmula: $\% \mathrm{G}=\left(\sum \mathrm{ni} \times 4\right)$, em que $\sum$ ni é o número total de sementes germinadas. O IVG foi calculado pela seguinte fórmula: IVG = $\mathrm{G} 1 / \mathrm{N} 1+\mathrm{G} 2 / \mathrm{N} 2+\mathrm{Gn} / \mathrm{Nn}$, em que $\mathrm{G}$ é o número de sementes germinadas e $\mathrm{N}$ o número de dias após a semeadura.

Para verificação da presença de compostos secundários voláteis em $H$. suaveolens foi extraído óleo essencial de 50 gramas de folhas picotadas, em três repetições. O óleo foi obtido por hidrodestilação (arraste a vapor), durante quatro horas consecutivas, em aparelho do tipo Clevenger, seco com sulfato de sódio anidro, o qual foi retirado por filtração simples.

$A$ análise qualitativa foi feita em aparelho Shimadzu CG - 17A equipado com detector de ionização de chama (FID). A partir do tempo de retenção dos hidrocarbonetos e de todos compostos foi calculado o Índice de Kovats (IK) ou índice de retenção relativo de cada um deles (Van Den Dool \& Kratz, 1963). O percentual de cada composto foi obtido através da área integral dos respectivos picos relacionados com a área total de todos os constituintes da amostra. Os constituintes foram identificados através da comparação dos respectivos espectros de massa em duas livrarias computadorizadas (NIST21 e NIST107) e através da comparação de IKs com os dados da literatura (Adams, 1995).

Em todos os experimentos estudados foram empregados o delineamento inteiramente casualizado (DIC). Os dados obtidos foram submetidos à análise de variância utilizando-se o Sistema de Análise de Variância para Dados Balanceados (SISVAR ${ }^{\circledR}$ ) (Ferreira, 2003). Para comparação dos contrastes entre médias dos tratamentos foi utilizado o teste de Tukey ao nível de $5 \%$ de probabilidade.

\section{RESULTADO E DISCUSSÃO}

Na Tabela 1 estão os dados de \%G e o IVG das três espécies nos tratamentos propostos. A \%G não apresentou diferença entre os tratamentos, porém para o IVG foram observadas diferenças para alface e rabanete. No tratamento controle (NESF) a germinação das três espécies foi acima de $90 \%$, o que condiz com a germinação recomendada pelos produtores.

Para o IVG de alface os substratos não esterilizados apresentaram índice superior aos substratos esterilizados. Essas diferenças provavelmente não foram causadas por efeito alelopático das folhas visto que não foram observadas diferenças entre os tratamentos com e sem material vegetal. Porém, para rabanete NEF o IVG foi maior, podendo ser considerado um efeito benéfico à germinação desta espécie. Spiassi e colaboradores (2011), trabalhando com palhada de milho incorporada em substrato observaram interações positivas e negativas dependentes da espécie alvo utilizada. Isso confirma o que foi observado neste trabalho, onde as respostas variam de acordo com a espécie.

O IVG tem mostrado sensibilidade aos efeitos alelopáticos, sendo um parâmetro interessante a ser avaliado (Tur et al., 2010). O atraso ou a diminuição no tempo gasto para a germinação podem ser revertidos em lucros ou prejuízos no campo, principalmente quando se trata de espécies que possuem um ciclo de vida curto.

Sartor et al. (2009), trabalhando com efeito alelopático de Pinus taeda na germinação e no desenvolvimento de plântulas de Avena strigosa, observaram muitas modificações nos padrões de crescimento da espécie utilizada como modelo neste estudo. Estes autores trabalharam com extratos e verificaram potencialização do efeito de acordo com o aumento da concentração. Um dos problemas que pode ser encontrado na utilização de extratos são os possíveis efeitos osmóticos causados pelos extratos que podem dificultar o entendimento do que é efeito alelopático e o que é efeito de mudanças na dinâmica de absorção de água ou mesmo de modificações de pH (Tur et al., 2010).

Comparando-se as três espécies testadas houve diferença na resposta germinativa (Tabela 2 ). Em virtude das médias de sorgo e alface terem sido inferiores (b) à de rabanete (a), possivelmente essas

TABELA 1: Porcentagem de germinação (\%G) e Índice de Velocidade de Germinação (IVG) nos tratamentos EF, ESF, NEF e NESF, para sorgo, alface e rabanete.

\begin{tabular}{lcccccc}
\hline & \multicolumn{2}{c}{ Sorgo } & \multicolumn{2}{c}{ Alface } & \multicolumn{2}{c}{ Rabanete } \\
Tratamento & IVG & $\% \mathbf{~ G}$ & IVG & $\% G$ & IVG & $\% G$ \\
\hline EF & 9,72 & $95^{\mathrm{a}}$ & $7,54^{\mathrm{b}}$ & $93^{\mathrm{a}}$ & $11,67^{\mathrm{c}}$ & $99^{\mathrm{a}}$ \\
ESF & 7,10 & $85^{\mathrm{a}}$ & $7,95^{\mathrm{b}}$ & $96^{\mathrm{a}}$ & $13,02^{\mathrm{bc}}$ & $97^{\mathrm{a}}$ \\
NEF & 12,48 & $90^{\mathrm{a}}$ & $12,47^{\mathrm{a}}$ & $100^{\mathrm{a}}$ & $24,14^{\mathrm{a}}$ & $100^{\mathrm{a}}$ \\
NESF & 10,27 & $92^{\mathrm{a}}$ & $11,87^{\mathrm{a}}$ & $95^{\mathrm{a}}$ & $14,72^{\mathrm{b}}$ & $98^{\mathrm{a}}$ \\
\hline
\end{tabular}

*As letras iguais não diferem entre si pelo teste de Tukey a $5 \%$ de probabilidade

Rev. Bras. Pl. Med., Botucatu, v.14, n.3, p.487-493, 2012. 
TABELA 2. Germinação total tratada pelo teste de Tukey com Análise de Variância para as sementes de sorgo, alface e rabanete.

\begin{tabular}{ll}
\hline Espécie & Médias* $^{*}$ \\
\hline Sorgo & $19.106250^{\mathrm{b}}$ \\
Alface & $18.087500^{\mathrm{b}}$ \\
Rabanete & $22.231250^{\mathrm{a}}$ \\
\hline
\end{tabular}

*valores com índices iguais não diferem entre si estatisticamente

duas cultivares são mais sensíveis aos testes que a cultivar de rabanete utilizada. Resultados assim foram observados por Félix et al. (2007), que em estudos com Amburana cearensis, também constatou maior suscetibilidade do alface comparada ao sorgo.

Para os tratamentos, as médias finais da germinação, independente da espécie foi igual estatisticamente para substrato esterilizado e sem folhas (ESF) e substrato esterilizado com folhas (EF), e diferente das médias finais dos tratamentos para 0 substrato não esterilizado e sem folhas (NESF) e o não esterilizado e com folhas (NEF), que entre si também apresentaram médias estatisticamente iguais (Tabela 3). Essas diferenças entre os tratamentos ESF, EF, e NESF, NEF podem estar relacionadas à presença de microorganismo no substrato utilizado, uma vez que as diferenças observadas se referem ao substrato esterilizado comparado ao substrato não esterilizado. Quanto à presença de folhas no substrato, os tratamentos EF e ESF apresentaram menor germinação, evidenciando que para os tratamentos não houve efeito alelopático mediada pelas folhas. O tratamento NEF apresentou a maior média de germinação, supondo que possa ter, através dos microorganismos, ocorrido a decomposição da matéria orgânica, deixando livre no substrato as substâncias presentes na folha, ou até mesmo, sintetizando compostos diferentes daqueles existentes inicialmente nas folhas, o que levou ao aumento na germinação das espécies testes, e potencial efeito alelopático positivo (Tabela 3 ).

Hasse et al. (2007) relatam que plantas medicinais e aromáticas podem controlar a existência

TABELA 3. Germinação média de sementes de sorgo, alface e rabanete em diferentes substratos: ESF, EF, NESF e NEF.

\begin{tabular}{ll}
\hline Tratamentos & Médias \\
\hline ESF & $17.783333^{\mathrm{b}}$ \\
EF & $18.483333^{\mathrm{b}}$ \\
NESF & $20.791667^{\mathrm{a}}$ \\
NEF & $22.175000^{\mathrm{a}}$ \\
\hline
\end{tabular}

*valores com índices iguais não diferem entre si estatisticamente de microrganismos no solo, o que altera também a dinâmica de estabelecimento de novas plântulas em determinado local.

Testes alelopáticos com metabólitos secundários são muito encontrados na literatura, porém, a maior parte destes testes é feita com extratos concentrados, ou até mesmo com óleos essenciais já extraídos da espécie utilizada. O que pode ser observado nesses testes é que a grande maioria das espécies trabalhadas apresenta potencial alelopático, como extratos de Leucaena leucocephala sobre a germinação de sementes de plantas invasoras e soja (Rosa et al., 2007), extratos de Eugenia dysenterica na germinação de alface (Giotto et al., 2007), extrato de leucena ( $L$. leucocephala) inibindo o desenvolvimento de milho, com redução do crescimento das raízes e do índice mitótico (Pires \& Oliveira, 2001). Ao utilizar folhas de $H$. suaveolens de forma bruta, sem utilização de óleo essencial ou mesmo extratos, ficam evidenciados de maneira mais próxima o que ocorre na natureza. Porém, quando se utiliza este método, a concentração de substâncias presentes no substrato fica inferior à utilizada em testes com óleo essencial puro ou com extratos de partes das plantas. Assim, resultados como inibição da germinação não foram encontradas neste trabalho.

Quanto ao tempo de germinação das sementes de alface, rabanete e sorgo nos diferentes tratamentos (EF, ESF, NEF e NESF), novamente podem ser agrupados quanto às diferenças estatísticas em substrato estéril e não esterilizado. As análises da germinação nos diferentes tratamentos (Figura 1), desconsiderando-se a separação por espécies, mostrou atraso na germinação na primeira coleta de dados quando comparados com as médias estimadas. O tratamento NEF foi o que apresentou a maior germinação na primeira análise, evidenciando o potencial alelopático positivo das folhas de $H$. suaveolens. A partir da segunda análise ( 24 horas) a germinação comporta-se de acordo com o esperado.

A extração de óleo essencial das folhas mostrou a presença de componentes com potencial alelopático. Por meio da análise qualitativa do óleo das folhas de $H$. suaveolens constatou-se a presença de terpenóides (Tabela 4). Entre os principais constituintes das amostras estão trans-cariofileno $(18,15 \%)$, beta-elemeno $(7,26 \%)$, óxido de cariofileno $(6,97 \%)$, germacreno d $(6,43 \%)$, espatulenol $(5,23 \%)$ e veridiflorol $(5,11 \%)$. O óleo essencial de $H$. suaveolens apresenta grandes variações de acordo com as condições onde as plantas se desenvolvem. Azevedo et al. (2002) e Oliveira et al. (2005) encontraram espatulenol como constituinte majoritário do óleo essencial de $H$. suaveolens provenientes do Cerrado Brasileiro e Martins e colaboradores (2006),

Rev. Bras. PI. Med., Botucatu, v.14, n.3, p.487-493, 2012. 

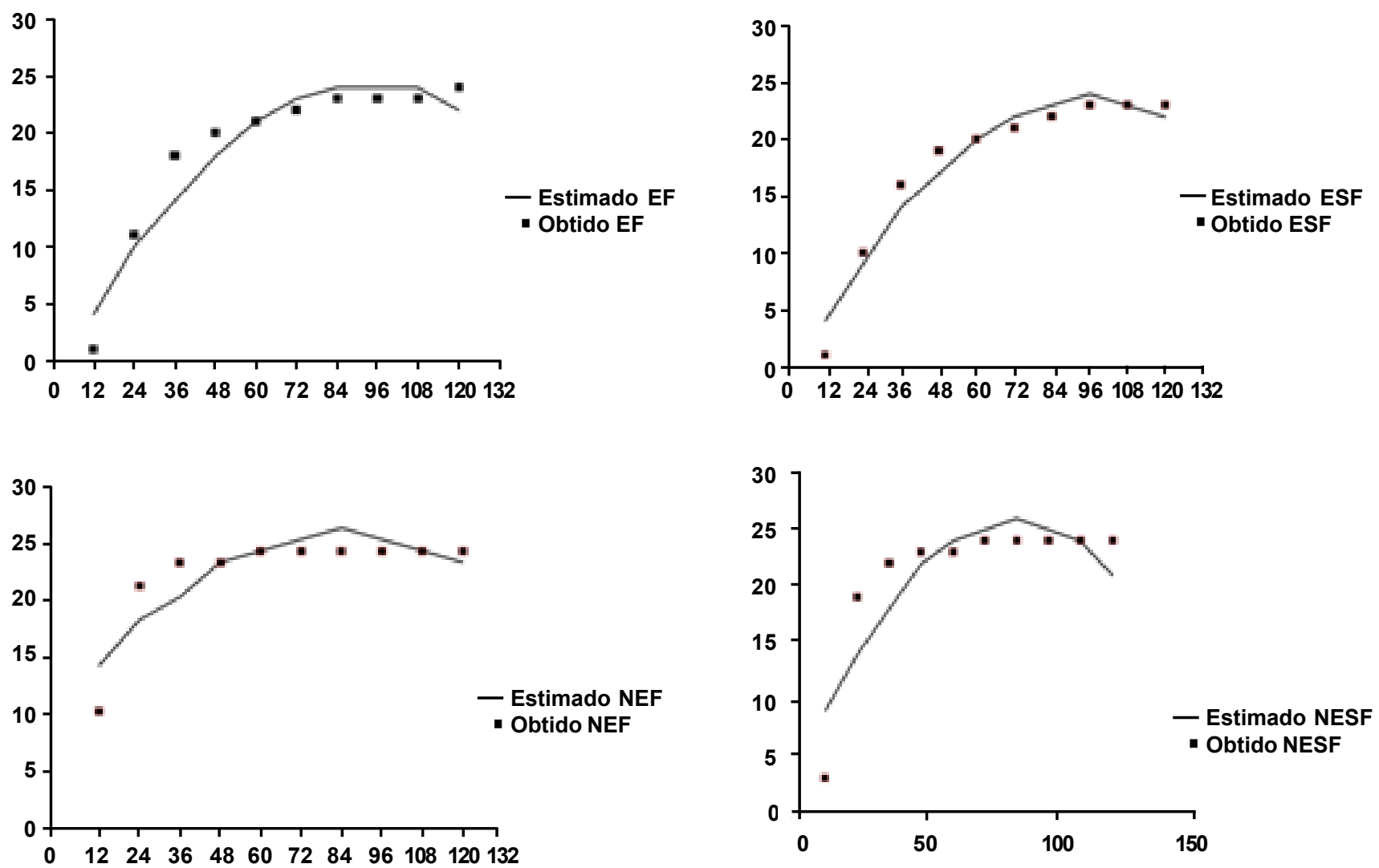

FIGURA 1. Médias obtidas e médias estimadas por teste estatístico, levando-se em consideração os tratamentos EF (A), ESF (B), NEF (C) e NESF (D) e o tempo de germinação de 12 a 120 horas, respectivamente.

TABELA 4. Porcentagem dos componentes do óleo essencial de $H$. suaveolens nas três amostras (HS) de plantas coletadas no cerrado de Boa Esperança.

\begin{tabular}{llllll}
\hline & IIK & Componente & HS 1 & HS 2 & HS 3 \\
\hline 1 & 976 & sabineno & 3,64 & - & - \\
2 & 978 & 1,3-octenol & - & - & - \\
3 & 1005 & I-felandreno & - & - & - \\
4 & 1031 & dl-limoneno & 1,36 & 0,61 & - \\
5 & 1062 & gama-terpineno & - & - & - \\
6 & 1088 & alfa-terpinoleno & - & 1,02 & - \\
7 & 1098 & cis-sabineno hydratado & - & - & - \\
8 & 1177 & terpineol-4 & 2,76 & 1,22 & - \\
9 & 1384 & beta-bourboneno & - & 1,67 & 0,92 \\
10 & 1391 & beta-elemeno & 9,60 & 16,30 & 28,55 \\
11 & 1404 & trans-cariofileno & - & 12,69 & 9,10 \\
12 & 1418 & beta-cariofileno & 2,30 & 0,56 & 3,76 \\
13 & 1433 & gamma-elemeno & 1,42 & 1,22 & - \\
14 & 1454 & alfa-humuleno & 2,86 & 1,80 & 0,98 \\
15 & 1480 & germacreno d & 15,55 & 2,12 & 1,61 \\
16 & 1513 & gama-cadineno & 1,22 & 1,51 & 1,35 \\
17 & 1524 & delta-cadineno & 0,44 & 0,53 & 0,94 \\
\hline & & & & & continua...
\end{tabular}

Rev. Bras. PI. Med., Botucatu, v.14, n.3, p.487-493, 2012. 
TABELA 4. Porcentagem dos componentes do óleo essencial de $H$. suaveolens nas três amostras (HS) de plantas coletadas no cerrado de Boa Esperança.

continuação...

\begin{tabular}{llllll}
\hline & 1IK & Componente & HS 1 & HS 2 & HS 3 \\
\hline 18 & 1549 & elemol & 0,79 & 1,13 & 0,00 \\
19 & 1565 & ledol & - & - & - \\
20 & 1576 & espatulenol & 4,25 & 5,59 & 5,86 \\
21 & 1581 & oxido de cariofileno & 2,50 & 8,65 & 9,78 \\
22 & 1590 & veridiflorol & 5,74 & 4,06 & 5,33 \\
23 & 1640 & epi-alfa-cadinol & 2,83 & 4,48 & 3,57 \\
24 & 1691 & juniper canfor & - & 0,57 & 0,45 \\
25 & 1956 & rimueno & 0,45 & - & - \\
26 & 1959 & cembreno & - & - & 0,82 \\
27 & 1960 & sandaracopimareno-15 & - & - & 0,25 \\
\hline & & Total identificado (\%) & 57,71 & 65,73 & 73,27 \\
\hline
\end{tabular}

1 Índice de Kovats experimental. - Composto não detectado na respectiva amostra

em casa de vegetação sob diferentes condições de fotoperíodo e adubação, encontraram globulol e desidroabietol, ambos resultados diferentes dos que foram encontrados no presente trabalho. Diferenças na composição de metabólitos secundários podem ser responsáveis pela variação de respostas alelopáticas encontradas na literatura.

O baixo potencial alelopático encontrado no presente trabalho pode estar relacionado a essa variação na produção de compostos secundários em função do estágio de desenvolvimento e do local de coleta. A análise dos resultados evidencia a necessidade de estudos com outras espécies alvo, com foco na presença de microorganismos, que podem estar relacionados com as respostas em testes alelopáticos resultante da interação entre solo e matéria vegetal, aliado aos diferentes compostos majoritários que podem ser encontrados na espécie em questão.

\section{CONCLUSÃO}

A presença de folhas de $H$. suaveolens no substrato favorece a germinação e propicia efeito promotor do IVG de rabanete. Existe uma interação entre a presença do material vegetal e a presença ou a ausência de microorganismos no substrato. Os testes alelopáticos quando realizados simulando as condições naturais (uso de folhas como fonte do agente químico e substrato não estéril) apresentam resultados diferentes daqueles em que a fonte é 0 extrato vegetal.

\section{REFERÊNCIA}

ADAMS, R.P. Identification of essential oil components by gas chromatography/mass spectroscopy. Ilinois: Allured Publishing Corporation, 1995, 469p.

ALVES, M.C.S. et al. Alelopatia de extratos voláteis na germinação de sementes e no comprimento da raíz de alface. Revista de Pesquisa Agropecuária Brasileira, v.39, n.11, p.1083-6, 2004.

AZEVEDO, N.R. et al. Essential oil chemotypes in Hyptis suaveolens from Brazilian Cerrado. Biochemical Systematics and Ecology, v.30, p.205-16, 2002.

DELACHIAVE, M.E.A.; RODRIGUES, J.D.; ONO, E.O. Efeito alelopático de Losna (Artemisia absinthium L.) na germinação de sementes de pepino, milho, feijão e tomate. Revista Brasileira de Sementes, v.21, n.2, p.265-9, 1999.

FALCÃO, D.Q.; MENEZES, F.S. Revisão etnofarmacológica, farmacológica e química do gênero Hyptis. Revista Brasileira de Farmácia, v.84, n.3, p.6974, 2003.

FELIX, R.A.Z. et al. Efeitos alelopáticos da Amburana cearensis L.(Fr.All.) AC Smith na germinação de sementes de alface (Lactuca sativa L.) e de rabanete (Raphanus sativus L.). Revista Brasileira de Biociências, v.5, supl. 2, p.138-40, 2007.

FERREIRA, D.F. Sisvar 4.3. 2003. Disponível em: <http:/ /www.dex.ufla.br/danielff/ sisvar>. Acesso em: 19 jun. 2008.

GIOTTO, A.C.; OLIVEIRA, S.C.C.; SILVA, J.G.P. Efeito alelopático de Eugenia dysenterica Mart. ex DC. Berg. (Myrtaceae) na germinação e no crescimento de Lactuca sativa L. (Asteraceae). Revista Brasileira de Biociências, v.5, supl. 2, p.600-2, 2007.

HASSE, I.; MAY-DE MIO, L.L.; LIMANETO, V.C. Efeito do pré-plantio com plantas medicinais e aromáticas no controle de Plasmodiophora brassicae. Summa Phytopathologica, v.33, n.1, p.74-9, 2007.

MARTINS, F.T. et al. Variação química do óleo essencial

Rev. Bras. Pl. Med., Botucatu, v.14, n.3, p.487-493, 2012. 
de Hyptis suaveolens (L.) Poit., sob condições de cultivo. Química Nova, v.29, n.6, p.1203-9, 2006.

MARTINS, F.T.; POLO, M. Aspectos anatômicos e moleculares do desenvolvimento reprodutivo em Hyptis suaveolens (L.) Poit.: relações entre fotoperíodo, densidade celular meristemática e padrão de expressão de um suposto homólogo do gene LEAFY de Arabidopsis. Revista Brasileira de Botânica, v.32, n.1, p.131-42, 2009.

MIRÓ, C.P.; FERREIRA, A.G.; AQUILA, M.E.A. Alelopatia de frutos de erva-mate (Ilex paraguariensis) no desenvolvimento do milho. Pesquisa Agropecuária Brasileira, v.33, n.8, p.1261-70, 1997.

OLIVEIRA, M.J. et al. Influence of growth phase on the essential oil composition of Hyptis suaveolens. Biochemical Systematics and Ecology, v.33, p.275-85, 2005.

PEERZADA, N. Chemical composition of the essential oil of Hyptis suaveolens. Molecules, v.2, p.165-8, 1997. PIRES, N.M.; OLIVEIRA, V.R. Alelopatia. In: OLIVEIRA, R.S.; CONSTANTIN, J. (Coords.). Plantas daninhas e seu manejo. Guaíba: Agropecuária, 2001, p.145-85. POLO, M. Ervas invasoras de uma cultura de milho no município de Campinas, Estado de São Paulo. 1982. 124p. Dissertação (Mestrado - Área de Concentração em Botânica) - Departamento de Ciências Biológicas, Universidade Estadual de Campinas, Campinas.

POLO, M.; FELIPPE, G.M. Germinação de ervas invasoras: efeito de luz e escarificação. Revista Brasileira de Botânica, v.6, p.55-60, 1983.

RICE, E.L. Allelopathy. 2.ed. New York: Academic Press,
1984, 424p.

ROSA, D.M. et al. Potencial alelopático de Leucaena leucocephala (Lam.) de Wit sobre a germinação de sementes de plantas invasoras e soja. Revista Brasileira de Biociências, v.5, supl. 2, p.525-7, 2007. SARTOR, L.R. et al. Alelopatia de acículas de Pinus taeda na germinação e no desenvolvimento de plântulas de Avena strigosa. Ciência Rural, v.39, n.6, p.1653-9, 2009. SILVA, A.F. et al. Composição química do óleo essencial de Hyptis suaveolens (L.) Poit. (Lamiaceae). Revista Brasileira de Plantas Medicinais, v.6, n.1, p.1 7, 2003. SOARES, G.L.G.; VIEIRA, T.R. Inibição da germinação e do crescimento radicular de alface (cv. "Grand Rapids") por extratos aquosos de cinco espécies de Gleicheniaceae. Revista Floresta e Ambiente, v.7, n.1, p.180-97, 2000.

SOUZA, L.S. et al . Efeito alelopático de capim-braquiária (Brachiaria decumbens) sobre o crescimento inicial de sete espécies de plantas cultivadas. Planta daninha, v.24, n.4, p.657-68, 2006.

SPIASSI, A. et al. Alelopatia de palhadas de coberturas de inverno sobre o crescimento inicial de milho. Semina. Ciências Agrárias (Online), v.32, p.576-82, 2011.

TUR, C.M.; BORELA, J.; PASTORINI, L.H. Alelopatia de extratos aquosos de Duranta repens sobre a germinação e o crescimento inicial de Lactuca sativa e Lycopersicum esculentum. Biotemas, v.23, n.2, p.13-22, 2010.

VAN DEN DOOL, H.; KRATZ, P.D.J.A. Generalization of the retention index system including linear temperature programmed gas-liquid partition chromatography. Journal of Chromatography, v.11, p.463-71, 1963. 